\title{
Adipose-derived mesenchymal stem cells ameliorate dibutyltin dichloride-induced chronic pancreatitis by inhibiting the PI3K/AKT/mTOR signaling pathway
}

\author{
XIANGXIANG XU*, HUAJUN YU*, LINXIAO SUN", CHENLEI ZHENG, \\ YUNFENG SHAN, ZHENXU ZHOU, CHENG WANG and BICHENG CHEN \\ Department of Surgery, Key Laboratory of Diagnosis and Treatment of Severe Hepato-Pancreatic Diseases of \\ Zhejiang Province, Zhejiang Provincial Top Key Discipline in Surgery, The First Affiliated Hospital of \\ Wenzhou Medical University, Wenzhou, Zhejiang 325000, P.R. China
}

Received September 21, 2019; Accepted January 17, 2020

DOI: $10.3892 / \mathrm{mmr} .2020 .10995$

\begin{abstract}
Adipose-derived mesenchymal stem cells (ASCs) play a positive role in tissue injury repair and regeneration. The aim of this study was to determine whether ASCs could ameliorate chronic pancreatitis (CP) induced by the injection of dibutyltin dichloride (DBTC) and to elucidate its potential mechanisms. Furthermore, this study also explored whether there was a significant difference if the ASCs were injected via the inferior vena cava or the left gastric artery. CP was induced in rats by a single intravenous administration of DBTC, and the accumulation of collagen and apoptotic rates of pancreatic acinar cells were analyzed. According to the results, ASCs markedly reduced DBTC-induced pancreatic damage and collagen deposition in the rat model of CP. Moreover, ASCs significantly decreased pancreatic cell apoptosis by regulating the expression levels of caspase-3, BAX and Bcl-2. These effects were observed regardless of whether the injection was in the inferior vena cava or the left gastric artery. It was also found that the expression levels of phosphorylated PI3K, AKT and mTOR in pancreatic tissues of the DBTC-induced $\mathrm{CP}$ model group were significantly increased, while the expression levels of phosphorylated PI3K, AKT and mTOR in the two treatment groups were markedly decreased. ASCs noticeably suppressed the PI3K/AKT/mTOR pathway in the
\end{abstract}

Correspondence to: Dr Bicheng Chen or Dr Cheng Wang, Department of Surgery, Key Laboratory of Diagnosis and Treatment of Severe Hepato-Pancreatic Diseases of Zhejiang Province, Zhejiang Provincial Top Key Discipline in Surgery, The First Affiliated Hospital of Wenzhou Medical University, Nanbaixiang Street, Wenzhou, Zhejiang 325000, P.R. China

E-mail: bichengchen@hotmail.com

E-mail: wangchengmandy@126.com

${ }^{*}$ Contributed equally

Key words: stem cell, DBTC, chronic pancreatitis pancreatic tissue of DBTC-induced CP. This study indicated that ASCs protect against pancreatic fibrosis by modulating the PI3K/AKT/mTOR pathway, and have the potential to be a new strategy for the treatment of $\mathrm{CP}$ in the future.

\section{Introduction}

The etiology of chronic pancreatitis (CP) is most commonly related to alcohol abuse, the incidence rate for clinical cases increased significantly from $2.94 / 100,000$ persons between 1977-1986 to 4.35/100,000 persons between 1997-2006 (1). $\mathrm{CP}$ is characterized by exocrine and endocrine pancreatic insufficiency, persistent or recurrent inflammation, fibrosis and macrophage infiltration (2). The main clinical symptom of $\mathrm{CP}$ is abdominal pain (3). The specific pathogenesis of $\mathrm{CP}$ is not clear, leading to insufficient diagnosis and treatment. At present, the treatment of $\mathrm{CP}$ is limited to symptomatic treatment rather than treatment based on the etiology and pathogenesis of the disease (4). In some cases, partial or total resection of the pancreas is an effective surgical treatment for CP-related abdominal pain if other treatments are ineffective $(5,6)$. Due to the chronicity and constant inflammation of $\mathrm{CP}$, it is necessary to seek a treatment plan that is highly effective and presents a low risk to patients. Therefore, mesenchymal stem cell therapy has the potential to be an effective means of treatment.

Mesenchymal stem cells are considered to be pluripotent cells, which are present in adult bone marrow, the umbilical cord, endodontic pulp and other organs (7). They have the potential to differentiate into mesenchymal tissue lineages, including bone, fat and muscle $(8,9)$. Mesenchymal stem cells have been used to treat pancreatic endocrine dysfunction in type 1 diabetes and have considerable efficacy $(10,11)$. Mesenchymal stem cells can inhibit the activation of T lymphocytes (12), and the proliferation of B lymphocytes (13) and natural killer cells (14). They also have immunomodulatory functions that provide a promising therapeutic strategy to regulate immune responses in immune-mediated diseases (15).

There are a number of possible sources of mesenchymal cells, but those derived from adipose tissue are convenient 
and abundant (16). Studies have shown that the transplantation of adipose-derived mesenchymal stem cells (ASCs) markedly improves revascularization and tissue perfusion in limb ischemia (17). Various studies have demonstrated that ASCs have a treatment effect for severe acute pancreatitis (AP) (18), type 1 diabetes $(19,20)$ and experimental colitis (21) in animal models. ASCs are currently being tested in clinical trials for the treatment of transsphincteric cryptoglandular fistulas (22), Crohn's-related rectovaginal fistula (23), refractory rheumatoid arthritis (24), severe osteoarthritis of the knee (25), systemic sclerosis (26) and other diseases (27). Continuous regional arterial infusion with low-molecular-weight heparin exhibits strong therapeutic effects in the case of severe AP with a high level of safety (28). In the present study, the therapeutic effects of ASCs were studied in a rat dibutyltin dichloride (DBTC)-induced CP model via inferior vena cava and left gastric artery injection. It was found that ASCs could delay the progression of CP by suppressing the PI3K/AKT/mTOR pathway.

\section{Materials and methods}

Animals andtreatment. A total of 24 adultmale Sprague-Dawley (SD) rats weighing approximately $280 \mathrm{~g}$ were obtained from the animal center at Wenzhou Medical University. All animal work was approved by the Animal Ethics Committee of Wenzhou Medical University. The rats were kept in an environment with a comfortable humidity and were given no less than ten hours of light each day at $28-30^{\circ} \mathrm{C}$. The animals were allowed free access to food and water and were acclimated to the environment for one week before the experiment began. $\mathrm{CP}$ was induced by a single $8 \mathrm{mg} / \mathrm{kg}$ intravenous administration of DBTC (Schering AG) and ASCs were then introduced via different routes of administration. Lastly, the pancreatic tissue was removed for further study. The experiment schedule is shown in Fig. 1. The rats were randomly divided into four groups with six rats per group: Control group (rats received normal saline); DBTC-induced CP model group (CP was induced in the rats via DBTC injection through the tail vein); ASC-treated group I (after DBTC-induced CP, the rats were anesthetized via an intraperitoneal injection of 5\% chloral hydrate, $300 \mathrm{mg} / \mathrm{kg}$, and received 2,000,000 cells $/ \mathrm{kg}$ ASCs via inferior vena cava injection); and ASC-treated group II (after DBTC-induced CP, the rats were anesthetized via an intraperitoneal injection of $5 \%$ chloral hydrate, $300 \mathrm{mg} / \mathrm{kg}$, and received 2,000,000 cells/kg ASCs by left gastric artery injection). All the rats, except for the control, were given $10 \%$ ethanol per day for 10 weeks after the DBTC injection to induce pancreatic fibrosis; the rats in the control group were given normal drinking water. In the third week, the rats in the ASC-treated group I received 2,000,000 cells/kg ASCs by inferior vena cava injection, and the rats in the ASC-treated groups II received 2,000,000 cells/kg ASCs by left gastric artery injection. The rats in the DBTC-induced CP model group and the control group received the equivalent volume of normal saline by intravenous injection. At the end of the experiment, all animals were euthanized by intraperitoneal injection of pentobarbital sodium $(200 \mathrm{mg} / \mathrm{kg})$. Finally, pancreatic tissue samples were collected and stored at $-80^{\circ} \mathrm{C}$ for further examination.
Cell culture. SD rat ASCs were purchased from Cyagen Biosciences, Inc., and cultured in OriCell ${ }^{\mathrm{TM}}$ Adipose-Derived Mesenchymal Stem Cell Growth Medium(Cyagen Biosciences, Inc.). Cells were incubated at $37^{\circ} \mathrm{C}$ in an atmosphere containing $5 \% \mathrm{CO}_{2}$ and passaged using $0.25 \%$ trypsin-EDTA solution before the treatment began.

Histological features of pancreatic tissue. Pancreatic tissue samples were placed on standardized $1 \times 1 \mathrm{~cm}$ pieces of paper. They were fixed in $10 \%$ paraformaldehyde overnight at $4^{\circ} \mathrm{C}$, embedded in paraffin and sectioned into $6-\mu \mathrm{m}$-thick slices. The slices were then stained using Sirius red stain (staining: Sirius red dye for $1 \mathrm{~h}$; and Mayer hematoxylin for $15 \mathrm{~min}$ at $\left.25^{\circ} \mathrm{C}\right)$. The sections were then observed under a light microscope (Nikon Corporation) to determine pancreatic pathological changes.

Immunohistochemistry assays. Pancreatic tissue samples were fixed in $10 \%$ paraformaldehyde overnight at $4^{\circ} \mathrm{C}$, embedded in paraffin and sectioned into $4-\mu \mathrm{m}$-thick slices. The slices were then incubated in an oven overnight at $55-65^{\circ} \mathrm{C}$. After $30 \mathrm{~min}$ of deparaffinization in xylene, the slices were rehydrated in a graded ethanol series. The slices were then incubated in citrate buffer for $5 \mathrm{~min}$ at $25^{\circ} \mathrm{C}$ and treated in a microwave oven for 15 min for antigen repair at $65-75^{\circ} \mathrm{C}$.

The sections were washed with $3 \% \mathrm{H}_{2} \mathrm{O}_{2}$ and blocked with $10 \%$ goat serum (OriGene Technologies, Inc.) for $60 \mathrm{~min}$ at $37^{\circ} \mathrm{C}$. The samples were incubated with the primary antibody against collagen type I (1:1,000; cat. no. 66761-1-Ig; ProteinTech Group, Inc.) and collagen type III (1:1,000; cat. no. 22734-1-AP; ProteinTech Group, Inc.) overnight at $4^{\circ} \mathrm{C}$. Species-specific secondary antibody (1:200; A0277; Beyotime Institute of Biotechnology) was added to the pancreatic tissue sections for $60 \mathrm{~min}$ at $37^{\circ} \mathrm{C}$. Finally, the pancreatic tissue sections were stained with diaminobenzidine for $10 \mathrm{~min}$ at $25^{\circ} \mathrm{C}$, and the cell nuclei were stained with hematoxylin for $3 \mathrm{~min}$ at $25^{\circ} \mathrm{C}$. After sealing the sections with neutral resin, they were examined under a light microscope.

Western blot analysis. The pancreatic tissues were incubated for $60 \mathrm{~min}$ in a mixture of radioimmunoprecipitation assay buffer (Beyotime Institute of Biotechnology), phosphatase inhibitor (Roche Diagnostics $\mathrm{GmbH}$ ) and phenylmethylsulfonyl fluoride (Beyotime Institute of Biotechnology) at a ratio of 100:10:1, which was used to extract proteins from the pancreatic tissue. The tissue lysate was then centrifuged at $12,000 \mathrm{x}$ g for $20 \mathrm{~min}$ at $4^{\circ} \mathrm{C}$, and the supernatant was collected. The total protein concentration was determined by a BCA protein kit (Beyotime Institute of Biotechnology). The mixture of protein samples and gel-loading buffer was boiled for $5 \mathrm{~min}$ and then stored overnight at $4^{\circ} \mathrm{C}$. Protein samples $(16 \mu \mathrm{l})$ were isolated by SDS-PAGE (10\%) and then transferred to PVDF membranes (EMD Millipore). Membranes were blocked with $5 \%$ skimmed milk powder for $2 \mathrm{~h}$ at $25^{\circ} \mathrm{C}$. The blots were incubated with primary antibodies at $4^{\circ} \mathrm{C}$ overnight, followed by incubation with a horseradish peroxidase-conjugated goat anti-rabbit IgG antibody (1:10,000; BioSharp, Technology Inc.) at room temperature for $1 \mathrm{~h}$. Primary antibodies to the following proteins were used: Collagen type I (1:1,000; cat. no. 66761-1-Ig; ProteinTech Group, Inc.), Collagen type III 


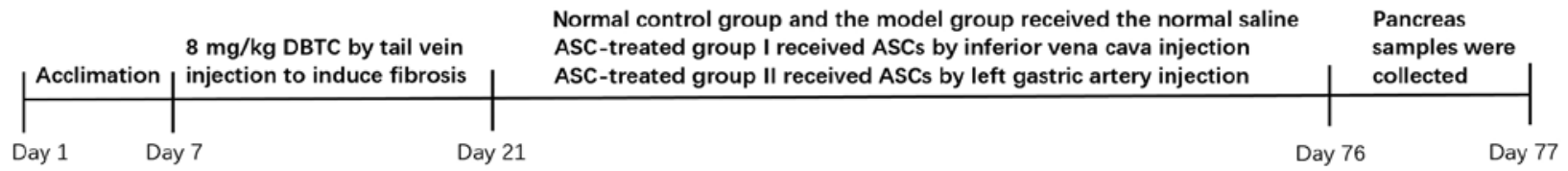

Figure 1. Experiment schedule. Rats were left to adapt to the environment for one week, following which a single injection of DBTC was administered in the tail vein and $10 \%$ ethanol to induce chronic pancreatitis. After two weeks of modeling, rats were injected with ASCs and euthanized at eight weeks. ASC, adipose-derived mesenchymal stem cell; DBTC, dibutyltin dichloride.

(1:1,000; cat. no. 22734-1-AP; ProteinTech Group, Inc.), tumor necrosis factor- $\alpha$ (TNF- $\alpha$; 1:1,000; cat. no. ab6671; Abcam), PI3K (1:1,000; cat. no. 4249S; Cell Signaling Technology, Inc.), phosphorylated (p)-PI3K (1:1,000; cat. no. 4228S; Cell Signaling Technology, Inc.), AKT (1:1,000; cat. no. 4691T; Cell Signaling Technology, Inc.), p-AKT (1:1,000; cat. no. 4060S; Cell Signaling Technology, Inc.), mTOR (1:1,000; cat. no. 2983S; Cell Signaling Technology, Inc.), p-mTOR (1:1,000; cat. no. 5536S; Cell Signaling Technology, Inc.), BAX (1:1,000; 2772S; Cell Signaling Technology, Inc.), BCl-2 (1:1,000; cat. no. ab59348; Abcam), caspase-3 (1:1,000; cat. no. 9662S; Cell Signaling Technology, Inc.) and GAPDH (1:1,000; cat. no. 5174S; Cell Signaling Technology, Inc.). Finally, protein bands were visualized by an enhanced chemiluminescence detection system (VisionWorks 8.20; Analytik Jena US LLC).

Statistical analysis. Data are presented as mean \pm SD and analyzed using one-way ANOVA followed by Tukey's post hoc test. Statistical significance was determined as $\mathrm{P}<0.05$. The data were obtained from independent experiments conducted three times.

\section{Results}

ASC treatment ameliorates pancreatic fibrosis and alleviates collagen accumulation. The level of pancreatic fibrosis and collagen accumulation was visualized by Sirius Red staining. Rats from the control group showed a standard histological structure with pancreatic acinar cells closely arranged around the islets. Samples from the DBTC-induced $\mathrm{CP}$ model group showed significant fibrous connective tissue hyperplasia, acinar cell atrophy and necrosis. However, ASC treatment markedly improved pancreatic morphology and architecture. There was no accumulation of collagen in the healthy pancreatic cells, but there was an accumulation of collagen in the wall of the healthy blood vessels (Fig. 2A-a). In the DBTC-induced CP model group, pancreatic cells were surrounded by collagen, and the normal structure of the pancreatic tissue was destroyed (Fig. 2A-b). However, ASC treatment markedly decreased collagen accumulation and damage in pancreatic tissues of DBTC-induced CP (Fig. 2A-c and A-d). Moreover, it was found that ASC treatment markedly decreased the expression levels of collagen type I, collagen type III and TNF- $\alpha$ in pancreatic tissues of DBTC-induced CP (Fig. 2B-F). However, there was no statistical difference in the expression level of collagen type I, collagen type III and TNF- $\alpha$ between the ASC-treated group I and the ASC-treated group II. Overall, these findings demonstrated that ASCs could preserve pancreatic structure and inhibit collagen accumulation and pancreatic fibrogenesis, regardless of the site of injection (inferior vena cava or left gastric artery).

ASCs decrease DBTC-induced pancreatic cell apoptosis. In this study, the expression levels of apoptosis-related proteins of the pancreatic tissues were examined using western blotting. The apoptosis-related proteins include BAX, Bcl-2 and caspase-3. As shown in Fig. 3, ASC treatment markedly increased the expression level of the anti-apoptotic protein Bcl-2. ASC treatment also significantly decreased the expression levels of the pro-apoptotic protein BAX. The expression levels of caspase-3 were significantly increased in the $\mathrm{CP}$ model group. After ASC treatment, the expression level of caspase-3 was markedly decreased. However, there was no statistical difference in the expression of BAX, Bcl-2 and caspase-3 between ASC-treated group I and ASC-treated group II. These results demonstrated that ASCs could reduce DBTC-induced pancreatic cell apoptosis regardless of the site of injection (inferior vena cava or left gastric artery).

ASCs suppress the PI3K/AKT/mTOR pathway in $D B T C$-induced $C P$. To explore whether there is a link between pancreatic fibrosis and the PI3K/AKT/mTOR pathway, the $\mathrm{PI} 3 \mathrm{~K} / \mathrm{AKT} / \mathrm{mTOR}$ pathway in pancreatic tissue was analyzed. The expressions of $\mathrm{p}$-PI3K, $\mathrm{p}$-AKT and $\mathrm{p}$-mTOR were markedly increased in the DBTC-induced CP model group. However, ASC treatment significantly decreased the expression levels of the p-PI3K, p-AKT and p-mTOR compared to the DBTC-induced CP model group (Fig. 4A-C). There was no statistical difference in the expression levels of the p-PI3K, p-AKT and p-mTOR between the ASC-treated groups I and II. These results demonstrated that the ASCs suppressed activation of the PI3K/AKT/mTOR pathway (Fig. 4).

\section{Discussion}

$\mathrm{CP}$ is characterized by inflammation and persistent pancreatic damage with collagen accumulation that ultimately leads to pancreatic fibrosis $(29,30)$. Hepatocyte damage and fibrosis have a close relationship with hepatic stellate cell activation (31). Stellate cells that resemble hepatic stellate cells and have similar functions were also found in the pancreas (32). Pancreatic tissue damage and inflammation in CP that release cytokines can lead to the activation of pancreatic stellate cells (PSCs), which ultimately leads to pancreatic fibrosis (33). ASCs were able to suppress PSC activation and proliferation, as well as inducing their apoptosis (34). ASCs could have a potential protective effect for pancreatic tissue damage and pancreatic fibrosis. At present, the underlying mechanism of how ASCs alleviate pancreatic fibrosis remains unclear. In the 


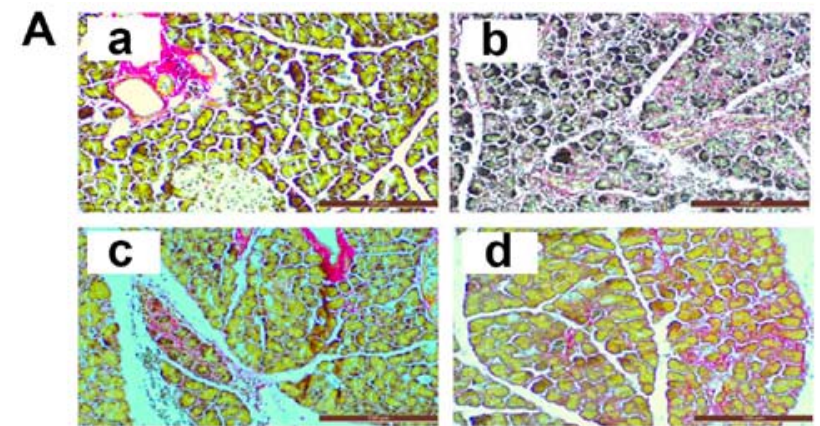

Sirius red
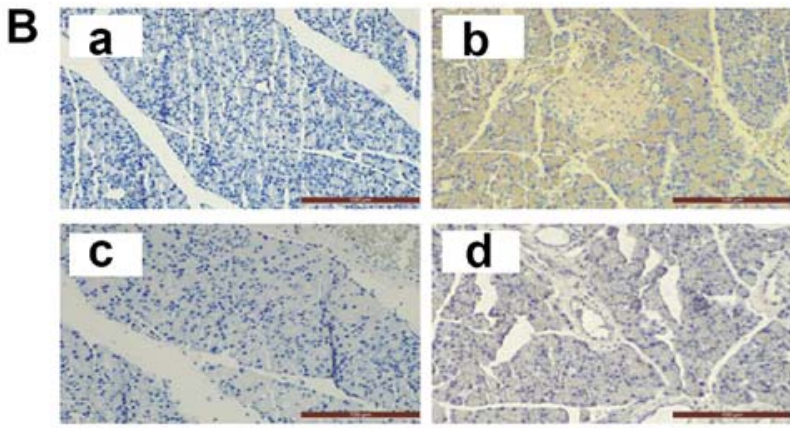

$\mathrm{COI}$
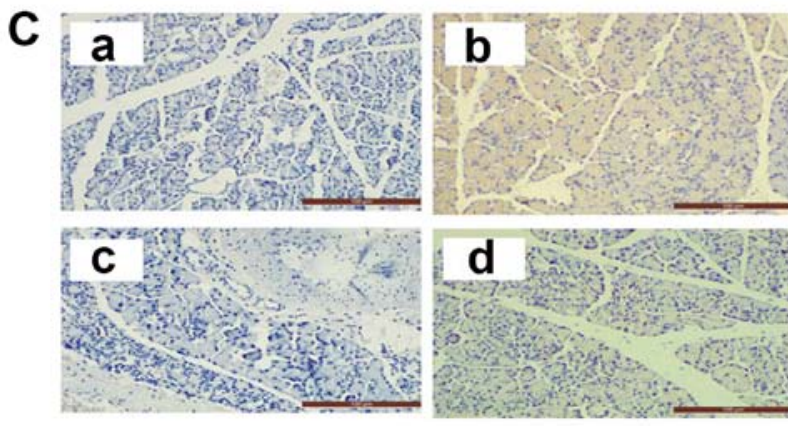

COIII
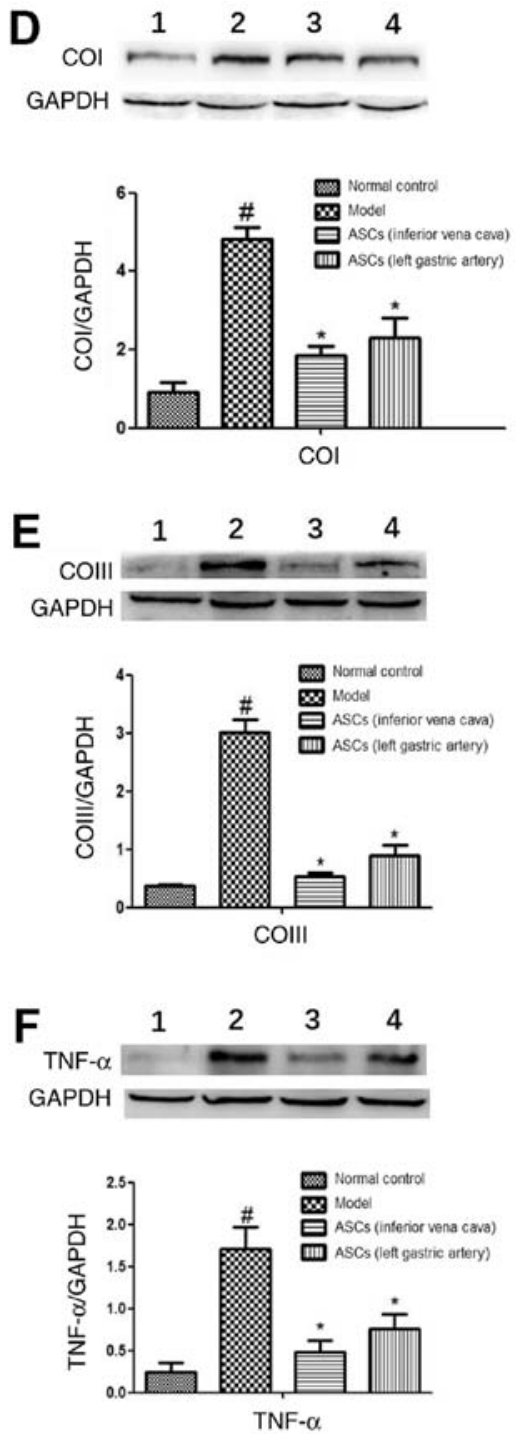

Figure 2. ASCs reduce pancreatic tissue collagen accumulation in DBTC-induced pancreatic fibrosis. (A) Pancreatic collagen was observed by Sirius Red staining (magnification, x200). Using immunohistochemical staining (magnification, x200) the expression of (B) COI and (C) COIII was detected. Images represent: a, the control; b, the DBTC-induced chronic pancreatitis model; $\mathrm{c}$, the ASC-treated group I; and d, the ASC-treated group II. Using western blotting the expression of (D) COI, (E) COIII and (F) TNF- $\alpha$ were detected. Bands represent: 1, the control; 2, the DBTC-induced chronic pancreatitis model; 3, the ASC-treated group I; and 4, the ASC-treated group II. Data are presented as mean $\pm \mathrm{SEM}(\mathrm{n}=3)$. ${ }^{*} \mathrm{P}<0.05$ vs. Control group; ${ }^{*} \mathrm{P}<0.05$ vs. DBTC-induced chronic pancreatitis model group. ASC, adipose-derived mesenchymal stem cell; DBTC, dibutyltin dichloride; COI, collagen type I; COIII, collagen type III; TNF- $\alpha$, tumor necrosis factor- $\alpha$.

present study, $\mathrm{CP}$ was induced by a single intravenous administration of DBTC. The DBTC treatment caused severe injury and fibrosis of the pancreatic tissue, and ASCs treatment reduced the degree of pancreatic fibrosis and damage. These results indicated that ASCs are able to alleviate DBTC-induced pancreatic damage.

Collagen type I and III are overexpressed in pancreatic fibrosis, and numerous studies have found that specific signaling molecules, such as Sma- and Mad-related proteins, mitogen-activated protein kinases, and peroxisome proliferator-activated receptor $g$ participate in the synthesis of proteins of the extracellular matrix. Activation of these pathways leads to collagen accumulation and accelerates fibrotic progression (35-37). TNF- $\alpha$ is a monokine that displays pro-inflammatory properties. It is produced in the pancreas in the early stages of AP and is detected in high amounts in both blood and pancreatic tissue (38). TNF- $\alpha$ also occurs in the early stages of $\mathrm{CP}$, and its expression has been observed in acinar cells, as well as in inflamed cells (39). Studies have revealed that TNF- $\alpha$ is also important in the development of CP by affecting PSCs (40). In a healthy pancreas, collagen type IX dominates, while type I is mainly produced in response to TNF- $\alpha$ (41). In the present study, it was also found that DBTC injection leads to collagen accumulation in the pancreatic tissues, as shown by Sirius Red staining, and ASC treatment could markedly reduce collagen accumulation in the pancreatic tissues of DBTC-induced CP. Moreover, ASC treatment notably suppressed the expressions of TNF- $\alpha$, collagen type I and collagen type III in pancreatic tissue. These results indicated that ASCs decrease the accumulation of collagen in pancreatic tissue and reduce the degree of pancreatic fibrosis. 

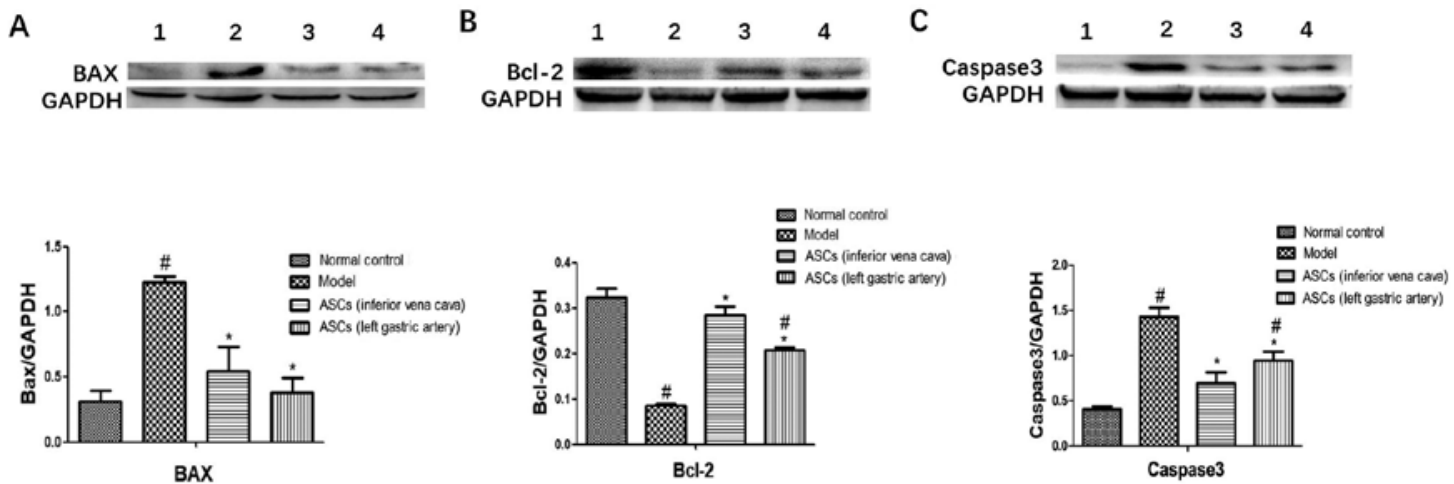

Figure 3. Effects of ASCs on pancreatic tissue apoptosis-related proteins in DBTC-induced pancreatic damage. Protein expression levels of (A) BAX, (B) Bcl-2 and (C) caspase-3 were examined by western blot analysis. Bands represent: 1, the control; 2, the DBTC-induced chronic pancreatitis model; 3, the ASC-treated group I; and 4, the ASC-treated group II. Data are presented as mean $\pm \mathrm{SEM}(\mathrm{n}=3)$. ${ }^{*} \mathrm{P}<0.05$ vs. Control group; ${ }^{*} \mathrm{P}<0.05$ vs. DBTC-induced chronic pancreatitis model group. ASC, adipose-derived mesenchymal stem cell; DBTC, dibutyltin dichloride.
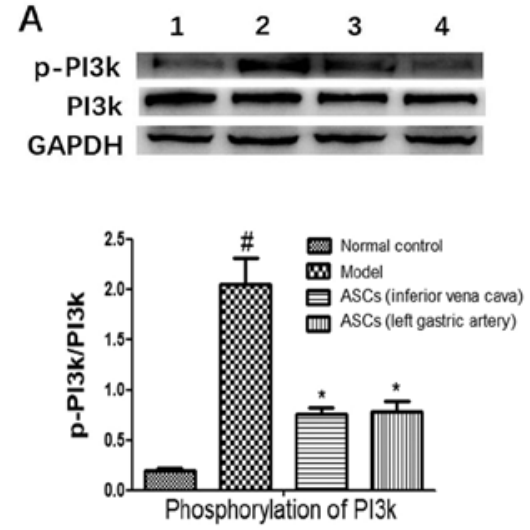
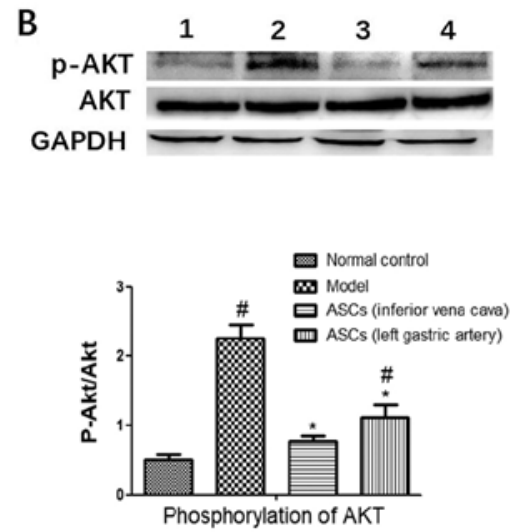
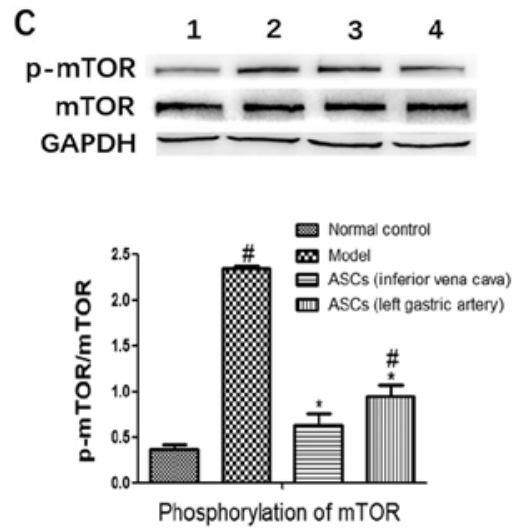

Figure 4. Effect of ASCs on protein phosphorylation in the PI3K/AKT/mTOR pathway of DBTC-induced chronic pancreatitis. Using western blotting the protein expression levels were examined: (A) p-PI3K and PI3K; (B) p-AKT and AKT; and (C) p-mTOR and m-TOR. Bands represent: 1, the control; 2, the DBTC-induced chronic pancreatitis model; 3, the ASC-treated group I; and 4, the ASC-treated group II. Data are presented as mean \pm SEM ( $=3$ ). ${ }^{\#} \mathrm{P}<0.05$ vs. Control group; " $\mathrm{P}<0.05$ vs. DBTC-induced chronic pancreatitis model group. ASCs, adipose-derived mesenchymal stem cell; DBTC, dibutyltin dichloride; p-, phosphorylated.

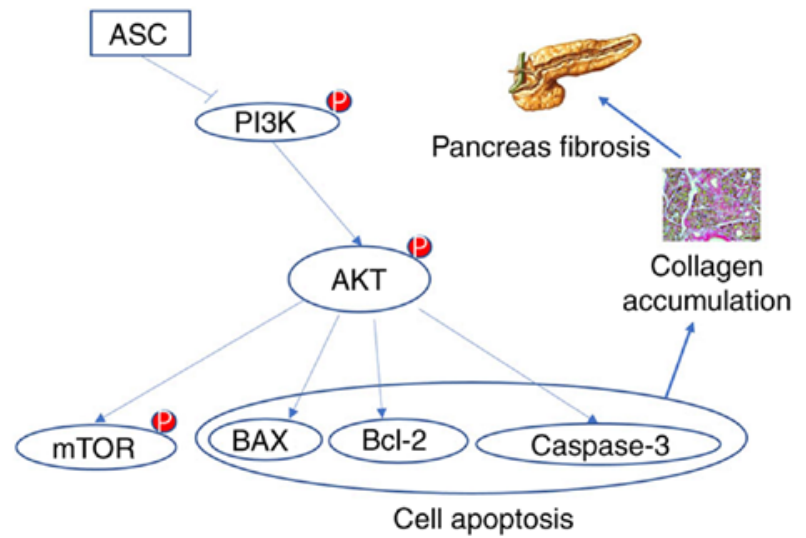

Figure 5. Illustration of the PI3K/AKT/mTOR signaling pathway. ASCs treatment inhibited the PI3K/AKT/mTOR signaling pathway, which ultimately reduced damage in rats with dibutyltin dichloride-induced chronic pancreatitis. ASC, adipose-derived mesenchymal stem cell; p-, phosphorylated.

The caspase family is a group of structurally related cysteine proteases in the cytosol that is closely related to cell proliferation, differentiation and migration (42). Caspases are divided into apoptotic and pro-inflammatory types, depending on their involvement in these cellular responses (43). Caspases also play a key role in the regulation of pancreatic acinar cell death (44). Caspase 3 is the prototype of the protein family and has an important role in the mechanism of apoptosis (45). Bcl-2 is an antiapoptotic protein that regulates mitochondrial pathways to led to antiapoptotic effects (46), and its expression is increased during the activation of PSC (47). Moreover, Bcl-2 inhibitors potentiate acinar cell necrosis in the in vitro model of pancreatitis (48). The expression of BAX is increased during apoptosis of pancreatic acinar cells during induction AP (49). In the present study, ASC treatment markedly improved the expression levels of Bcl-2 and significantly suppressed the expression levels of BAX and caspase-3. These results demonstrated that the therapeutic effect of ASCs inhibit DBTC-induced pancreatic fibrosis and reduce pancreatic cell apoptosis.

The PI3K/AKT/mTOR pathway is over-activated in pancreatic neuroendocrine tumor pathogenesis (50-55), breast cancer brain metastases (56) and colorectal cancer (57). The $\mathrm{PI} 3 \mathrm{~K} / \mathrm{AKT} / \mathrm{mTOR}$ signaling pathway is closely related to cell proliferation, differentiation, apoptosis, exercise, metabolism and autophagy $(58,59)$. The inhibition of this pathway 
contributes to the treatment of cancer patients, suggesting that it can be used as a target for the treatment of certain cancers (60). Previous studies indicated that saikosaponin $d$ prevents pancreatic fibrosis by reducing the autophagy of PSCs via the PI3K/AKT/mTOR pathway (61). In the present study, ASC treatment significantly decreased the phosphorylation of PI3K, AKT and mTOR in pancreatic tissue, suggesting that ASCs can successfully suppress the PI3K/AKT/mTOR pathway to reduce the degree of fibrosis in pancreatic tissue.

As discussed, pancreatic fibrosis is associated with the activation of PSCs; however, it is still unknown whether the ASC treatment of DBTC-induced CP suppresses the activation of PSCs by inhibiting the PI3K/AKT/mTOR pathway. This needs further verification. The present study demonstrated the potential use of mesenchymal stem cell therapy in the clinical treatment of CP. In clinical practice, AP can be treated by regional arterial infusion of drugs, with improved results compared with intravenous treatment $(62,63)$. Therefore, this study explored whether different approaches to $\mathrm{CP}$ could have an impact on the outcome of the treatment. It was shown that there was no statistically significant difference between the two treatment groups. The next step is to investigate whether ASCs can inhibit the activation of PSCs in vitro and its possible mechanism. In conclusion, this study demonstrated that ASCs alleviated DBTC-induced pancreatic fibrosis in rats by regulating the PI3K/AKT/mTOR pathway (Fig. 5). These findings may provide a new strategy for the treatment of CP.

\section{Acknowledgements}

Not applicable.

\section{Funding}

This study was supported by grants from The National Natural Science of China (grant no. 81770630), Natural Science Foundation of Zhejiang Province (grant no. LY16H030013) and Wenzhou Municipal Science and Technology Bureau (grant no. Y20150062).

\section{Availability of data and materials}

The data used to support the findings of this study are available from the corresponding author upon request.

\section{Authors' contributions}

XX carried out the experiment and wrote the article. HY participated in the experiment and made substantial contributions to the conception and design of the experiments. LS was involved in the article writing and interpretation of data. CZ, YS and ZZ contributed to the analysis and interpretation of data. CW and BC contributed to the design of the study. All authors read and approved the final manuscript.

\section{Ethics approval and consent to participate}

Animal Experiment Ethics Number of Experimental Animal Center of Wenzhou Medical University (policy no. wydw2019-0971).

\section{Patient consent for publication}

Not applicable.

\section{Competing interests}

The authors declare that they have no competing interests.

\section{References}

1. Yadav D, Timmons L, Benson JT, Dierkhising RA and Chari ST: Incidence, prevalence, and survival of chronic pancreatitis: A population-based study. Am J Gastroenterol 106: 2192-2199, 2011.

2. Lankisch PG: Natural course of chronic pancreatitis. Pancreatology 1: 3-14, 2001.

3. DiMagno MJ and Dimagno EP: Chronic pancreatitis. Curr Opin Gastroenterol 22: 487-497, 2006.

4. Andrén-Sandberg A, Hoem D and Gislason H: Pain management in chronic pancreatitis. Eur J Gastroenterol Hepatol 14: 957-970, 2002.

5. Argo JL, Contreras JL, Wesley MM and Christein JD: Pancreatic resection with islet cell autotransplant for the treatment of severe chronic pancreatitis. Am Surg 74: 530-536, 2008.

6. Dixon J, DeLegge M, Morgan KA and Adams DB: Impact of total pancreatectomy with islet cell transplant on chronic pancreatitis management at a disease-based center. Am Surg 74: 735-738, 2008.

7. da Silva Meirelles L, Chagastelles PC and Nardi NB: Mesenchymal stem cells reside in virtually all post-natal organs and tissues. J Cell Sci 119: 2204-2213, 2006.

8. Pittenger MF, Mackay AM, Beck SC, Jaiswal RK, Douglas R, Mosca JD, Moorman MA, Simonetti DW, Craig S and Marshak DR: Multilineage potential of adult human mesenchymal stem cells. Science 284: 143-147, 1999.

9. Jiang Y, Jahagirdar BN, Reinhardt RL, Schwartz RE, Keene CD, Ortiz-Gonzalez XR, Reyes M, Lenvik T, Lund T, Blackstad M, et al: Pluripotency of mesenchymal stem cells derived from adult marrow. Nature 418: 41-49, 2002.

10. D'Addio F, Valderrama Vasquez A, Ben Nasr M, Franek E, Zhu D, Li L, Ning G, Snarski E and Fiorina P: Autologous nonmyeloablative hematopoietic stem cell transplantation in new-onset type 1 diabetes: A multicenter analysis. Diabetes 63: 3041-3046, 2014.

11. Frumento D, Ben Nasr M, El Essawy B, D'Addio F, Zuccotti GV and Fiorina P: Immunotherapy for type 1 diabetes. J Endocrinol Invest 40: 803-814, 2017.

12. Krampera M, Glennie S, Dyson J, Scott D, Laylor R, Simpson E and Dazzi F: Bone marrow mesenchymal stem cells inhibit the response of naive and memory antigen-specific $\mathrm{T}$ cells to their cognate peptide. Blood 101: 3722-3729, 2003.

13. Corcione A, Benvenuto F, Ferretti E, Giunti D, Cappiello V, Cazzanti F, Risso M, Gualandi F, Mancardi GL, Pistoia V and Uccelli A: Human mesenchymal stem cells modulate B-cell functions. Blood 107: 367-372, 2006.

14. Sotiropoulou PA, Perez SA, Gritzapis AD, Baxevanis CN and Papamichail M: Interactions between human mesenchymal stem cells and natural killer cells. Stem Cells 24: 74-85, 2006.

15. Nauta AJ and Fibbe WE: Immunomodulatory properties of mesenchymal stromal cells. Blood 110: 3499-3506, 2007.

16. Jurgens WJ, Oedayrajsingh-Varma MJ, Helder MN, Zandiehdoulabi B, Schouten TE, Kuik DJ, Ritt MJ and van Milligen FJ: Effect of tissue-harvesting site on yield of stem cells derived from adipose tissue: Implications for cell-based therapies. Cell Tissue Res 332: 415-426, 2008.

17. Bura A, Planat-Benard V, Bourin P, Silvestre JS, Gross F, Grolleau JL, Saint-Lebese B, Peyrafitte JA, Fleury S, Gadelorge M, et al: Phase I trial: The use of autologous cultured adipose-derived stroma/stem cells to treat patients with non-revascularizable critical limb ischemia. Cytotherapy 16: 245-257, 2014.

18. Kim HW, Song WJ, Li Q, Han SM, Jeon KO, Park SC, Ryu MO, Chae HK, Kyeong K and Youn HY: Canine adipose tissue-derived mesenchymal stem cells ameliorate severe acute pancreatitis by regulating $\mathrm{T}$ cells in rats. J Vet Sci 17: 539-548, 2016. 
19. Kang HM, Kim J, Park S, Kim J, Kim H, Kim KS, Lee EJ, Seo SI, Kang SG, Lee JE and Lim H: Insulin-secreting cells from human eyelid-derived stem cells alleviate type I diabetes in immunocompetent mice. Stem Cells 27: 1999-2008, 2009.

20. Bassi ÊJ, Moraes-Vieira PM, Moreira-Sá CS, Almeida DC, Vieira LM, Cunha CS, Hiyane MI, Basso AS, Pacheco-Silva A and Câmara NO: Immune regulatory properties of allogeneic adipose-derived mesenchymal stem cells in the treatment of experimental autoimmune diabetes. Diabetes 61: 2534-2545, 2012.

21. Lopez-Santalla M, Mancheño-Corvo P, Escolano A, Menta R, DelaRosa O, Abad JL, Büscher D, Redondo JM, Bueren JA, Dalemans W, et al: Biodistribution and efficacy of human adipose-derived mesenchymal stem cells following intranodal administration in experimental colitis. Front Immunol 8: 638, 2017.

22. Dozois EJ, Lightner AL, Mathis KL, Chua HK, Kelley SR, Fletcher JG, Dietz AB, Friton JJ, Butler GW and Faubion WA: Early results of a phase I trial using an adipose-derived mesenchymal stem cell-coated fistula plug for the treatment of transsphincteric cryptoglandular fistulas. Dis Colon Rectum 62: 615-622, 2019.

23. Sanz-Baro R, García-Arranz M, Guadalajara H, de la Quintana P, Herreros MD and García-Olmo D: First-in-human case study: Pregnancy in women with crohn's perianal fistula treated with adipose-derived stem cells: A safety study. Stem Cells Transl Med 4: 598-602, 2015.

24. Álvaro-Gracia JM, Jover JA, García-Vicuña R, Carreño L, Alonso A, Marsal S, Blanco F, Martínez-Taboada VM, Taylor P Martín-Martín C, et al: Intravenous administration of expanded allogeneic adipose-derived mesenchymal stem cells in refractory rheumatoid arthritis (Cx611): Results of a multicentre, dose escalation, randomised, single-blind, placebo-controlled phase Ib/IIa clinical trial. Ann Rheum Dis 76: 196-202, 2017

25. Pers YM, Rackwitz L, Ferreira R, Pullig O, Delfour C, Barry F, Sensebe L, Casteilla L, Fleury S, Bourin P, et al: Adipose mesenchymal stromal cell-based therapy for severe osteoarthritis of the knee: A phase I dose-escalation trial. Stem Cells Transl Med 5 $847-856,2016$

26. Guillaume-Jugnot P, Daumas A, Magalon J, Jouve E, Nguyen PS, Truillet R, Mallet S, Casanova D, Giraudo L, Veran J, et al: Autologous adipose-derived stromal vascular fraction in patients with systemic sclerosis: 12-month follow-up. Rheumatology (Oxford) 55: 301-306, 2016.

27. Díez-Tejedor E, Gutiérrez-Fernández M, Martínez-Sánchez P, Rodríguez-Frutos B, Ruiz-Ares G, Lara ML and Gimeno BF: Reparative therapy for acute ischemic stroke with allogeneic mesenchymal stem cells from adipose tissue: A safety assessment: A phase II randomized, double-blind, placebo-controlled, single-center, pilot clinical trial. J Stroke Cerebrovasc Dis 23 : 2694-2700, 2014.

28. Ke L, Ni HB, Tong ZH, Li WQ, Li N and Li JS: Efficacy of continuous regional arterial infusion with low-molecular-weight heparin for severe acute pancreatitis in a porcine model. Shock 41: 443-448, 2014.

29. Sarles H: Etiopathogenesis and definition of chronic pancreatitis Dig Dis Sci 31 (9 Suppl): 91S-107S, 1986.

30. Witt H, Apte MV, Keim V and Wilson JS: Chronic pancreatitis: Challenges and advances in pathogenesis, genetics, diagnosis, and therapy. Gastroenterology 132: 1557-1573, 2007.

31. Friedman SL: Hepatic stellate cells: Protean, multifunctional, and enigmatic cells of the liver. Physiol Rev 88: 125-172, 2008

32. Omary MB, Lugea A, Lowe AW and Pandol SJ: The pancreatic stellate cell: A star on the rise in pancreatic diseases. J Clin Invest 117: 50-59, 2007.

33. Xu M, Wang G, Zhou H, Cai J, Li P, Zhou M, Lu Y, Jiang X, Huang $H$, Zhang Y and Gong A: TGF- $\beta 1$-miR-200a-PTEN induces epithelial-mesenchymal transition and fibrosis of pancreatic stellate cells. Mol Cell Biochem 43: 1161-1168, 2017.

34. Yu FX, Su LF, Dai CL, Wang Y, Teng YY, Fu JH, Zhang QY and Tang YH: Inhibition of pancreatic stellate cell activity by adipose-derived stem cells. Hepatobiliary Pancreat Dis Int 14 215-221, 2015

35. Zhang SK, Tsui NC, Li DH, Yao GW and Wang YN: Expression of transforming growth factor beta1/Sma- and Mad-related proteins in rat with chronic pancreatitis induced by dibutyltin dichloride. Pancreas 39: 252-253, 2010.

36. Schwer CI, Mutschler M, Stoll P, Goebel U, Humar M, Hoetzel A and Schmidt R: Carbon monoxide releasing molecule-2 inhibits pancreatic stellate cell proliferation by activating p38 mitogen-activated protein kinase/heme oxygenase-1 signaling. Mol Pharmacol 77: 660-669, 2010.
37. Fortunato F, Berger I, Gross ML, Rieger P, Buechler MW and Werner J: Immune-compromised state in the rat pancreas after chronic alcohol exposure: The role of peroxisome proliferator-activated receptor gamma. J Pathol 213: 441-452, 2007.

38. Mayer J, Rau B, Gansauge F and Beger HG: Inflammatory mediators in human acute pancreatitis: Clinical and pathophysiological implications. Gut 47: 546-552, 2000.

39. Xie MJ, Motoo Y, Su SB and Sawabu N: Expression of tumor necrosis factor-alpha, interleukin-6, and interferon-gamma in spontaneous chronic pancreatitis in the WBN/Kob rat. Pancreas 22: 400-408, 2001.

40. Mews P, Phillips P, Fahmy R, Korsten M, Pirola R, Wilson J and Apte M: Pancreatic stellate cells respond to inflammatory cytokines: Potential role in chronic pancreatitis. Gut 50: 535-541, 2002.

41. Poudel B, Ki HH, Lee YM and Kim DK: Collagen I-induced dendritic cells activation is regulated by TNF- $\alpha$ lpha production through down-regulation of IRF4. J Biosci 40: 71-78, 2015.

42. Li J and Yuan J: Caspases in apoptosis and beyond. Oncogene 27: 6194-6206, 2008.

43. Man SM and Kanneganti TD: Converging roles of caspases in inflammasome activation, cell death and innate immunity. Nat Rev Immunol 16: 7-21, 2016.

44. Mareninova OA, Sung KF, Hong P, Lugea A, Pandol SJ, Gukovsky I and Gukovskaya AS: Cell death in pancreatitis: Caspases protect from necrotizing pancreatitis. J Biol Chem 281: 3370-3381, 2006

45. Pop C and Salvesen GS: Human caspases: Activation, specificity, and regulation. J Biol Chem 284: 21777-21781, 2009.

46. Leist M and Jäättelä M: Four deaths and a funeral: From caspases to alternative mechanisms. Nat Rev Mol Cell Biol 2: 589-598, 2001.

47. Shen J, Wan R, Hu G, Yang L, Xiong J, Wang F, Shen J, He S, Guo X, Ni J, et al: miR-15b and miR-16 induce the apoptosis of rat activated pancreatic stellate cells by targeting Bcl-2 in vitro. Pancreatology 12: 91-99, 2012.

48. Sung KF, Odinokova IV, Mareninova OA, Rakonczay Z Jr, Hegyi P, Pandol SJ, Gukovsky I and Gukovskaya AS: Prosurvival Bcl-2 proteins stabilize pancreatic mitochondria and protect against necrosis in experimental pancreatitis. Exp Cell Res 315: 1975-1989, 2009.

49. Gomez G, Lee HM, He Q, Englander EW, Uchida T and Greeley GH Jr: Acute pancreatitis signals activation of apoptosis-associated and survival genes in mice. Exp Biol Med (Maywood) 226: 692-700, 2001.

50. Djukom C, Porro LJ, Mrazek A, Townsend CM Jr, Hellmich MR and Chao C: Dual inhibition of PI3K and mTOR signaling pathways decreases human pancreatic neuroendocrine tumor metastatic progression. Pancreas 43: 88-92, 2014.

51. Briest $F$ and Grabowski P: PI3K-AKT-mTOR-signaling and beyond: The complex network in gastroenteropancreatic neuroendocrine neoplasms. Theranostics 4: 336-365, 2014.

52. Francois RA, Maeng K, Nawab A, Kaye FJ, Hochwald SN and Zajac-Kaye M: Targeting focal adhesion kinase and resistance to mTOR inhibition in pancreatic neuroendocrine tumors. J Nat Cancer Inst 107: pii: djv123, 2015.

53. Falletta S, Partelli S, Rubini C, Nann D, Doria A, Marinoni I, Polenta V, Di Pasquale C, Degli Uberti E, Perren A, et al: mTOR inhibitors response and mTOR pathway in pancreatic neuroendocrine tumors. Endocr Relat Cancer 23: 883-891, 2016.

54. Vandamme T, Beyens M, de Beeck KO, Dogan F, van Koetsveld PM, Pauwels P, Mortier G, Vangestel C, de Herder W, Van Camp G, et al: Long-term acquired everolimus resistance in pancreatic neuroendocrine tumours can be overcome with novel PI3K-AKT-mTOR inhibitors. Br J Cancer 114: 650-658, 2016.

55. Zitzmann K, De Toni EN, Brand S, Göke B, Meinecke J, Spöttl G, Meyer HH and Auernhammer CJ: The novel mTOR inhibitor RAD001 (everolimus) induces antiproliferative effects in human pancreatic neuroendocrine tumor cells. Neuroendocrinology 85 : 54-60, 2007.

56. Adamo B, Deal AM, Burrows E, Geradts J, Hamilton E, Blackwell KL, Livasy C, Fritchie K, Prat A, Harrell JC, et al: Phosphatidylinositol 3-kinase pathway activation in breast cancer brain metastases. Breast Cancer Res 13: R125, 2011.

57. Johnson SM, Gulhati P, Rampy BA, Han Y, Rychahou PG, Doan HQ, Weiss HL and Evers BM: Novel expression patterns of PI3K/Akt/mTOR signaling pathway components in colorectal cancer. J Am Coll Surg 210: 767-778, 2010. 
58. LoRusso PM: Inhibition of the PI3K/AKT/mTOR pathway in solid tumors. J Clin Oncol 34: 3803-3815, 2016.

59. Rodon J, Dienstmann R, Serra V and Tabernero J: Development of PI3K inhibitors: Lessons learned from early clinical trials. Nat Rev Clin Oncol 10: 143-153, 2013.

60. Engelman JA: Targeting PI3K signalling in cancer: Opportunities, challenges and limitations. Nat Rev Cancer 9: 550-562, 2009.

61. Cui LH, Li CX, Zhuo YZ, Yang L, Cui NQ and Zhang SK: Saikosaponin $\mathrm{d}$ ameliorates pancreatic fibrosis by inhibiting autophagy of pancreatic stellate cells via PI3K/Akt/mTOR pathway. Chem Biol Interact 300: 18-26, 2019.

62. Hirota M, Shimosegawa T, Kitamura K, Takeda K, Takeyama Y, Mayumi T, Ito T, Takenaka M, Iwasaki E, Sawano H, et al: Continuous regional arterial infusion versus intravenous administration of the protease inhibitor nafamostat mesilate for predicted severe acute pancreatitis: A multicenter, randomized, open-label, phase 2 trial. J Gastroenterol: Nov 22, 2019 (Epub ahead of print).
63. Yong FJ, Mao XY, Deng LH, Zhang MM and Xia Q: Continuous regional arterial infusion for the treatment of severe acute pancreatitis: A meta-analysis. Hepatobiliary Pancreat Dis Int 14: 10-17, 2015

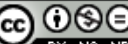

This work is licensed under a Creative Commons Attribution-NonCommercial-NoDerivatives 4.0 International (CC BY-NC-ND 4.0) License. 